\title{
Brunt of Global House Effect on Flora and Fauna
}

\author{
Dr.Anshu Srivastava*, Mr.Shakun Srivastava ${ }^{1}$
}

\begin{abstract}
The paper, illustrated the Brunt of global house effect on flora \& fauna, its underlying impacts, and attempts to spruce down it with the alliance of all individuals. The paper shows that, as an outcome of global warming, climate changes have reached irregular levels with rainfall and hurricanes of unusual intensity. Everyday gases such as carbon dioxide, carbon mono oxide are released to warm the earth, allowing it to be a place that can be inhabited by flora $\&$ fauna. However once the fauna, became higher in population, the warming of the earth was easier to identify.The paper also warns of what will happen if action is not taken in time and discusses positive and negative economic probabilities on flora \& fauna. Flora and fauna forms a major part of biodiversity. The paper concludes that it takes time for people to amend their attitudes. This paper puts forward an ecological model for understanding the impact of greenhouse warming on the natural environment.
\end{abstract}

Index Terms-Conservation, Causes, Ecosystem, Flora \&Fauna, Global warming, Greenhouse gases,

\section{INTRODUCTION}

The greenhouse effect is a process by which radiative energy leaving a planetary surface is absorbed by some atmospheric gases, called greenhouse gases. They transfer this energy to other components of the atmosphere, and it is re-radiated in all directions, including back down towards the surface. This transfers energy to the surface and lower atmosphere, so the temperature there is higher than it would be if direct heating by solar radiation were the only warming mechanism This mechanism is fundamentally different from that of an actual greenhouse, which works by isolating warm air inside the structure so that heat is not lost by convection. The greenhouse effect was discovered by Joseph Fourier in 1824, first reliably experimented on by John Tyndall in 1858, and first reported quantitatively by Svante Arrhenius in 1896.If an ideal thermally conductive blackbody was the same distance from the Sun as the Earth, it would have an expected blackbody temperature of $5.3{ }^{\circ} \mathrm{C}$. However, since the Earth reflects about $30 \%$ (or $28 \%$ ) of the incoming sunlight, the planet's actual blackbody temperature is about -18 or $-19{ }^{\circ} \mathrm{C}$, about $33^{\circ} \mathrm{C}$ below the actual surface temperature of about $14{ }^{\circ} \mathrm{C}$ or $15{ }^{\circ} \mathrm{C}$. The mechanism that produces this difference between the actual temperature and the blackbody temperature is due to the atmosphere and is known as the greenhouse effect.

*Department of Applied Science and Humanities, Kanpur Institute of Technology, email:mily13@rediffmail.com.Mob.no.9415556781

${ }^{1}$ Department of Mechanical engineering, Kanpur Institute of Technology, Kanpur-208001;

mail:shakun227@rediffmail.com.mob.no.9451918258

Corresponding author: Dr.Anshu Srivastava*
Global warming, a recent warming of the Earth's surface and lower atmosphere, is believed to be the result of a strengthening of the greenhouse effect mostly due to human-produced increases in atmospheric greenhouse gases.

\section{CAuses of Green House EfFect}

As said, the major cause of green house effect is the emission of green house gases like carbon dioxide, methane, nitrous oxide etc. into the atmosphere. The major source of carbon dioxide is the power plants. One of the man-made causes of the Green House effect is deforestation. Deforestation increases the amount of carbon-di-oxide in the atmosphere. Also, due to the disappearance of trees, photosynthesis cannot take place. Deforestation causes of the greenhouse effect. Deforestation is rampant today due to the increase in human civilization. The levels of deforestation have increased by about nine percent in recent times. Also, the burning of wood causes it to decay, therefore releasing more carbon-dioxide into the atmosphere. Greenhouse Gases also can be released into the atmosphere due to the burning of fossil fuels, oil, coal and gas. These materials are used increasingly and rampantly in Industries. Therefore Industries are also a major cause of the Greenhouse Effect. Other man-made causes of the increase in the Green house effect due to the emission of such gases are any all electrical appliances. Even the humble refrigerator in the house emits gases which contribute to the Greenhouse effect. These gases are known as Chlorofluorocarbons' (CFCs) and are used in refrigerators, aerosol cans, some foaming agents in the packaging industry, fire extinguisher chemicals and cleaners used in the electronic industry. Some processes of the cement manufacturing industries also act as a cause towards the Greenhouse effect. Other man-made processes that contribute and are a cause to the Greenhouse effect are burning of gasoline, oil and coal. Apart from these, some farming and land-use processes are a cause of the Green house effect. Most factories also produce many gases which last for a longer time in the atmosphere. These gases contribute to the green-house effect and also the global warming on the planet. These gases are not naturally available in the atmosphere.

\section{IMPACT OF GREEN HOUSE EFFECT ON EARTH AND PREVENTIVE MEASURES:}

Everyone has a responsibility to keep the earth safe and secure for the coming generations. Some immediate actions have to be taken for its security and to bring down the carbon dioxide emission and thus global warming:

1. Avoid the use of fossil fuels and rely on gas energy since the carbon compounds emitted by this is 
comparatively smaller.

2. Reduce the use of plastics as it destroys both atmosphere and land and Turn off computers, fans and bulbs while not in use and this help to reduce the energy consumption.

3. The use of wind power is an efficient method and factories must try to use this as source of electricity where ever possible and Plant as much trees as you can. Trees and plants can protect the atmosphere and soil as it is the best source of oxygen.

4. It is advisable to use sprinklers or drip - irrigation for plants and vegetables. It helps to reduce the loss of too much water at the same time make the surroundings more cool.

5. Vehicles are to be properly maintained so that the fuel consumption is reduced and emission of toxic gases is minimal. Pool a car to office or work place and walk to nearby places.

6. Buy only energy efficient home appliances. Be selective while you purchase and thus reduce the waste of products.

7. Wastes are to be properly treated. Use compost pit to dump degradable waste and recycle the plastic wastes. Proper sewage system is a necessary to protect rivers and lakes.Use water judiciously, as it is going to be a scarce commodity. Protect the rivers and lakes properly.

8.Protect oceans as it is the rich reservoir of vast amount of valuable flora and fauna. Educate the masses so that everyone is aware of the problem his action causes to earth.

\section{GReEn House EFFECT FACTS, DATA AND STATISTICS}

The data in the following set of tables, compiled by Dr. Richard Lindzen, an atmospheric scientist from MIT, only goes back to the mid 19th century; there are only about 150 years of data. Per-WWI data could be skewed. Depending on whether or not that is true, or even so, there is only about a 0.5 (one-half degree) centigrade change in global temperature that is clearly indicated. But what if the recent 25 year rising trend doesn't fall? What are the 500 year trends, year by year? Do we know? What are the 10,000 year trends? What if the earth really is warming - what if the data takes another leap, then another, instead of settling back to the 150 year mean? Do we combat this by curtailing and controlling all burning? Why instead don't we simply replace more of the $40 \%$ of forests that have been lost in the last 150 years, and restore to life $30 \%$ of the deserts that have marched forward over the last 150 years? We can plant trees in the cities while we're at it, to ameliorate the hugely significant additional effect of the urban heat islands of our world's new mega-cities. Do we strip the last forests to grow biofuel, instead of simply constructing (usually on rooftops) photovoltaic and solar-thermal arrays that consume - by well over two orders of magnitude - far less space? Wouldn't we rather replace desert with rangeland and farms, and rangeland and farms with forest, and put canopies of green across our cities, rather than regulate all burning?

\section{Green House EfFect Statistics}

In green house statistics show about the behavior of the global mean temperature. While there is agreement regarding the historical data that does not mean that the resulting observations are very solid? The tables above and below this paragraph are the records commonly displayed by the IPCC. Interestingly, the record is essentially flat since 1995. The modest spike in 1998 is commonly associated with an El Nino. The temperature records reflected in these two tables are completely consistent with a rapid rise from 1976 to 1986 and a leveling off since. This would be more like what is referred to as a regime change than a response to global greenhouse warming.

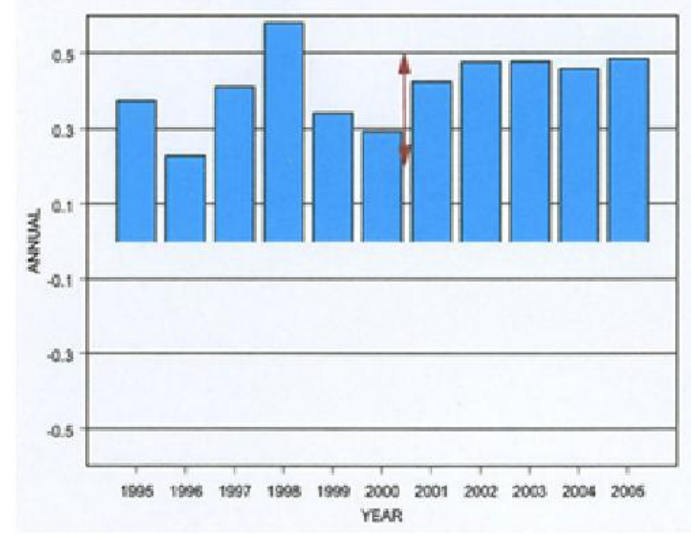

Fig-II Global mean annual surface temperature per year from 1995 through 2005

When considering global temperature trends it is important to take into account uncertainty bands. When this is done, as the table below indicates, there is no basis for claiming an significant global warming trend since 1986, though there might very well be one.

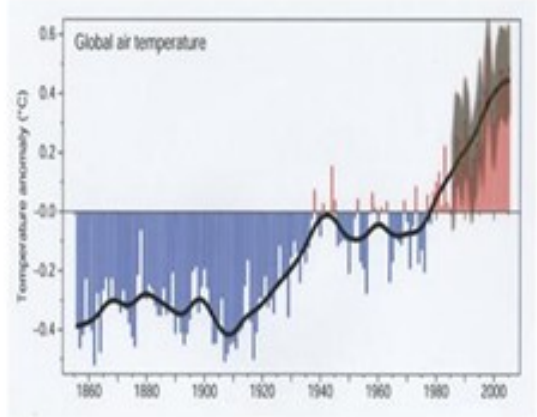

Fig-II Global mean annual surface temperature uncertainity bands per year from 1985 through 2005

It is sometimes claimed that the recent warming period involves much more rapid warming than the mean warming for the past century or so. This is, of course, true of any warming period in a record that includes periods of cooling as well as periods of relatively stationary temperature. For example, the rate of warming during 1910-1940 is somewhat more rapid than the recent rate. Moreover, if one looks for short periods, there is no difficulty in finding rates that are many times the rate over the last century.

\section{Green House EFFECT AFFECTING THE VARIOUS ECOSYSTEMS}

Greenhouse gases acts like a naturally blanket to the earth. 
They keep the temperature warmer and longer. How does this affect the environment and ecosystem? Greenhouse gases cause many environmental and ecosystem problems. Because the temperature across the globe is warmer, the glaciers and polar ice caps begin to melt. As a result, sea levels have risen between four to ten inches since 1990. The studies also show that floods and droughts are more severe. There are also more reports of extreme weathers like hurricane Katrina. There will be more tidal wave and beach erosion on the coasts. Many species of plants and animals also face the danger of extinction from global warming, because they will not be able to adapt to the change in the weather and climate. For instance, the rises in sea level can increase the salinity of freshwater across the globe. Many species of freshwater fish and plants will inevitably be affected by this change. It is estimated that over a million species of plants and animals will be extinct by 2050. Many of the native temperature resistant plant species are being wiped out of the earth. Vector borne diseases like dengue malaria are expected to increase sharply across the globe as the temperature variations make it more conducive for mosquitoes to thrive. Diarrhoeal disease which is associated with drought and flood is also expected to register a sudden increase. The effect which global warming has on the flora and fauna of sea is unprecedented. Majority of global greenhouse gas emissions occur in developed nations, but the developing countries suffer more as most of them are located in the tropics. Flora and Fauna:

Flora and fauna refer to plant and wildlife, respectively. The indigenous plant and wildlife of a geographical region is often referred to as that region's flora and fauna. Both are collective terms, referring to groups of plant or wildlife specific to a region or a time period. For example, the flora and fauna of a warm region may consist of tropical to warm-temperate vegetation and exotic species of birds. By definition, flora is a word of Latin origin referring to Flora, the goddess of flowers. Flora can refer to a group of plants, a disquisition of a group of plants, as well as to bacteria. Flora is the root of the word floral, which means pertaining to flowers. Fauna can refer to the animal life or classification of animals of a certain region, time period, or environment. Fauna is also of Latin origin. In Roman Mythology Fauna was the sister of Faunus, a good spirit of the forest and plains. The flora and fauna of any given region is usually explained in biological terms to include the genus and species of plant and animal life, their preferred growing or breeding habits, and their connection to one another in the environment as well. In addition to geographical groupings, environment also helps further classifications of flora and fauna. For example, aquatic flora and fauna of a region refers to the plant and animal life found in the waters in or surrounding a geographic region.

\section{CONSERVATION OF FLORA \& FAUNA FROM GREEN HOUSE EFFECT}

For most species (think of the hundreds of species of plants and animals including micro-organisms that live in any particular patch of bush) the option of movement down corridors or deliberate translocation is not available. It seems that the onset of the greenhouse effect will be too rapid for effective corridors to be established which could allow all the species within ecological communities to move down them. Few if any corridors of the size we can afford to retain or re-create will have the correct characteristics to allow the unimpeded movement of all species. The extensive clearance of land and its private ownership, as well as the monetary cost of establishing corridors severely constrain what can be done.This will require a massive expansion in resources and the rapid development of environmentally sensitive control techniques. For many developing countries like Indonesia, efforts to develop public awareness on global warming and climate changes are urgently needed in order to enhance public understanding on the issues.

\section{CONCLUSION}

Green House Effect the beginning of the Industrial Revolution brought many new, exciting inventions into our lives to simplify our lives and made them more efficient. We as individuals can do our part to reduce greenhouse gas emissions by making less-polluting choices. Purchase a fuel-efficient car or alternative fuel vehicle. Go to the MPCA's motor vehicle pollution page for more ideas. Do all your errands in one trip rather than several. Keep your car tuned and your tires fully inflated. Consider alternative means of transportation, such as the bus, your bike or just walking. Telecommute to work. In your home: Turn off lights, TVs and other electronic devices when not in use. Purchase energy efficient appliances that display the Energy Star label. Visit the Energy Star Web site more additional information. Replace incandescent lights with energy efficient fluorescent bulbs or light fixtures. Plant deciduous trees to shade your house. Trees can also remove 50 pounds of carbon from the air each year. Use a push mower. Compost your lawn clippings and leaf waste. Global warming is a problem, and it won't go away without the cooperation of the world and its inhabitants.

\section{REFERENCES}

[1] J ,McLean, 2009. The IPCC Can't Count its "Expert Scientists" Author and Reviewer Numbers are Wrong. International Climate and Environmental Change Assessment Project

[2] Royal Society (2005). "Joint science academies' statement: Global response to climate change". Retrieved 19 April 2009.

[3] David ,Archer (2005). "Fate of fossil fuel CO2 in geologic time" (PDF). Journal of Geophysical Research 110 (C9): C09S05.1C09S05.6. doi: 10. 1029/2004JC002625.

[4] KevinE.Trenberth,et al. (2007). "Chapter 3: Observations: Surface and Atmospheric Climate Change" (PDF). IPCC Fourth Assessment Report. Cambridge, United Kingdom and New York, NY, USA: Cambridge University Press. p. 244.

[5] J .McLean, 2007. An Analysis of the Review of the IPCC 4AR WG I Report. Science \& Public Policy Institute

[6] J.Knight, J.J.Kenney,C.Folland;G.Harris, A . Scaife et al. (August 2009). "Do Global Temperature Trends Over the Last Decade Falsify Climate Predictions? [In "State of the Climate in 2008"]". Bull. Amer. Meteor. Soc. 90

[7] Global temperature slowdown - not an end to climate change, UK Met Office, retrieved 2009-09-08

[8] Ceres (2004-04-28). "Global Warming Resolutions at U.S. Oil Companies Bring Policy Commitments from Leaders, and Record High Votes at Laggards". Press release.

[9] R.K. Trivedy,1994. Encyclopedia of Environmental Pollution \& control. Enviromedia, Karad, M.S., India.

[10] R.W. Wood,(1909). "Note on the Theory of the Greenhouse". 